ARTIGO

\title{
ECOINOVAÇÃO COMO VANTAGEM COMPETITIVA: UM ESTUDO DE CASO DA DELL INC. ${ }^{1}$
}

\author{
João Paulo Nascimento da Silva ${ }^{2}$ \\ Vitor Hugo Santos Ferreira \\ Rodrigo Marçal Gandia \\ Luiz Guilherme Rodrigues Antunes \\ Joel Yutaka Sugano
}

\begin{abstract}
RESUMO
O aumento das preocupações do mercado com as atividades sustentáveis gera oportunidades para o posicionamento das organizações, uma vez que esse posicionamento pode manter a empresa mais competitiva frente aos seus concorrentes. Dessa forma, faz-se necessário entender profundamente o fenômeno da ecoinovação (ou inovações sustentáveis), uma vez que tal tema proporciona diferencial competitivo aos negócios, bem como re-determina as bases econômicas vigentes. É sob esse contexto que se estabelece o objetivo deste artigo, que busca apresentar a prática de ecoinovação da Dell Inc. e revelar como ela pode se tornar fonte de vantagem competitiva para a referida empresa. Assim, partiu-se de um estudo descritivoexploratório, com uso do estudo de caso, no qual foram coletados dados por meio de uma entrevista semiestruturada e pesquisa documental no Plano Dell 2020. Os principais resultados obtidos foram: a empresa estudada apresenta elevado índice de práticas ecoinovativas e ao mesmo tempo visão, oportunidades e novos mercados por praticar tais inovações sustentáveis. Esses achados se encontram alinhados com a literatura sobre a respectiva temática.
\end{abstract}

Palavras-Chave: Inovação. Ecoinovação. Dell. Vantagem Competitiva.

\section{INTRODUÇÃO}

Desde a década de 1990, o tema do desenvolvimento sustentável revela uma corrente crescente de conscientização acerca do meio ambiente, restrição de recursos de consumo e energias renováveis, com foco nas futuras privações que o mercado pode sofrer. Nessa visão, há uma forte tendência cultural das empresas de se posicionarem junto às necessidades do mercado para garantir uma vantagem futura, seja por conscientização da organização ou vislumbre das potenciais oportunidades que tais mercados podem gerar.

\footnotetext{
${ }^{1}$ Como citar este artigo: SILVA, João Paulo Nascimento et al. Ecoinovação como vantagem competitiva: um estudo de caso da Dell INC. ForScience: revista científica do IFMG, Formiga, v. 6, n. 3, e00412, jul./dez. 2018.

${ }^{2}$ Autor para correspondência: João Paulo Nascimento da Silva, FSL, e-mail: jpnsilvas@gmail.com
} 
Na visão dos inovadores, o fato de inovar para gerar produtos sustentáveis que sejam capazes de salvar o meio ambiente, consiste na sua maior razão de ser (KOTLER; KARTAJAYA; SETIAWAN, 2010). Neste pensamento, muitos mercados e empresas buscam seu posicionamento nas ecoinovações, onde adquirem uma maior relação com o ambiente, assimilando as restrições esperadas como oportunidades de se tornarem empresas inovadoras, reinventando produtos e mercados.

Neste sentido, a ecoinovação parte do princípio das inovações sustentáveis, mesmo que ainda seja uma definição muito ampla e adaptada a diferentes conceitos, o que pode eventualmente reduzir seu valor prático. As ecoinovações são aqui entendidas como inovações com características que contribuem para desenvolvimento dos aspectos sociais, ecológicos e/ou econômicos, visando a sobrevivência a longo prazo do sistema econômico, o que depende da sua capacidade de criar e manter uma economia sustentável nos processos de longo prazo a que está inserida (CARRILLO-HERMOSILLA; DEL RIO; KÖNNÖLÄ, 2010).

Nesse sentido, o presente trabalho consiste em um estudo sobre a Dell Inc., que criou o plano "Dell 2020 Legacy of Good Plan", um plano para desenvolvimento de práticas mais sustentáveis da companhia, de modo a demostrar maior valor em suas atividades e, conforme apontado neste trabalho, de gerar vantagens competitivas futuras para a companhia.

A temática em estudo torna-se relevante devido às restrições esperadas para o mercado e à fortes pressões públicas para a adaptação das organizações à utilização dos recursos. Essa tendência traz oportunidades aos mercados e às empresas como a Dell Inc., que se identificam na busca por um posicionamento a fim de atender as necessidades futuras.

Neste sentido, esta pesquisa tem como objetivo apresentar a prática de ecoinovação da Dell Inc. e revelar como ela pode se tornar fonte de vantagem competitiva para a referida empresa. Advoga-se, portanto, que atualmente é possível compreender uma demanda por produtos ecoinovativos, embasados numa nova restrição de mercado, no qual a visão da empresa de inovar perante os mercados são entendidas como novas fontes sustentáveis e meios de se criar vantagens competitivas, ao longo prazo, na cadeia de produção.

Deste modo, este trabalho poderá contribuir com o entendimento das inovações sustentáveis como alternativas aos mercados futuros, e pode condicionar a vantagem competitiva, tendo em vista as restrições esperadas para a produção de materiais e de energia. 


\section{FUNDAMENTAÇÃO TEÓRICA}

Centrado nos conceitos de inovação e ecoinovação, o referencial procura apresentá-los como fundamentais para uma nova estrutura de mercado e consumo. O conteúdo desta revisão

de literatura visa apresentar e estruturar a base conceitual para o processo de busca de inovações ecológicas e/ou sustentáveis como ferramenta para uma nova forma de progresso e desenvolvimento.

\subsection{Inovação}

O tema inovação é uma constante em conceitos e discussões desde seus primórdios. O tema é definido de acordo com a necessidade de enquadramento ao momento econômico, o que, apesar de uma base conceitual, o torna um conceito mutável e evolutivo.

Segundo Schumpeter (1950), a inovação é a essência da mudança econômica. Assim, ao desenvolver o termo "destruição criativa", o autor buscou caracterizá-lo como uma forma ou método de transformação econômica que, pela constante busca pela criação de algo novo, destroem as bases então vigentes, estabelecendo novas regras ao modelo anterior.

Schumpeter (1939) ainda retrata a importância da inovação para a rendibilidade de longo prazo, pensamento intrínseco ao de Porter (1989) em vantagem competitiva sustentável. Para este autor, a inovação gera mudanças e renovações no mercado através da destruição e criação de novas empresas e novos modelos de negócio.

Já Porter e Van der Linde (1995) afirma que a inovação é a única forma de promover e sustentar uma vantagem sobre a concorrência. Contudo, segundo esse autor, esta inovação deve englobar e estar inserida numa direção estratégica consistente para o desenvolvimento da organização. Isto é, deve ocupar uma posição sustentável para enfrentar as forças da concorrência, de forma a superar seus rivais em termos de rentabilidade ao longo prazo.

De acordo com a Organização para a Cooperação e Desenvolvimento Econômico (OCDE), a inovação corresponde à implementação de uma nova ou melhorada solução para a empresa e a ecoinovação contribui para novas oportunidades de negócios que podem fazer organizações e setores mais competitivos (MANUAL DE OSLO, 2008). A OCDE, através do Manual de Oslo (2008) conceitua inovação como novo produto, novo processo, no sistema organizacional ou de marketing, abertura de um novo mercado, desenvolvimento de novas 
fontes de energia ou mudanças na estrutura organizacional, todos com o objetivo de reforçar a sua posição competitiva, aumentar o desempenho e o conhecimento.

Quanto às classificações, nas palavras de Schumpeter (1934), presentes no Manual de Oslo (2008, p. 32): “inovações radicais provocam grandes mudanças no mundo, enquanto inovações incrementais preenchem continuamente o processo de mudança". O Manual de Oslo (2008) apresenta a proposta de Schumpeter para uma relação entre os diferentes tipos de inovações: introdução de um novo produto ou mudança qualitativa em produto existente; inovação de processo que seja novidade para uma indústria; abertura de um novo mercado; desenvolvimento de novas fontes de suprimento de matéria-prima ou outros insumos; mudanças na organização industrial para a condução de um processo de reorganização que crie uma posição monopolista ou na ruptura de um monopólio existente.

Freeman (1988) tipifica a inovação como radical, sendo essa o desenvolvimento e introdução de um novo produto, processo ou forma de organização que represente uma ruptura com o padrão tecnológico anterior, alterando o perfil da economia mundial, impulsionando padrões de crescimento e originando novas indústrias e mercados. Já a inovação incremental se refere à introdução de qualquer tipo de melhoria em um produto, processo ou organização da produção dentro de uma empresa, sem alteração na estrutura industrial.

Kotler, Kartajaya e Setiawan (2010), em seu livro Marketing 3.0, apresenta o conceito de que os inovadores vão além da inovação incremental e abordam o desenvolvimento de inovações disruptivas (BOWER; CHRISTENSEN, 1995). Hart e Milstein (2004) rotulam a inovação incremental como um atributo estratégico para a empresa se tornar "verde". No entanto, os autores apontam que no caso da inovação disruptiva, o negócio busca ir além de se tornar "verde". Os autores afirmam ainda que a inovação e as transformações tecnológicas são a chave para o desenvolvimento sustentável.

Assim como todo desenvolvimento, as inovações também são caracterizadas, em alguns casos, pelo aparecimento de barreiras que, segundo Hadjimanolis (2003), são os fatores que inibem, colocam alguma obstrução ou inércia na inovação. Segundo Pinheiro (2002), para que as organizações lidem com a mudança, a incerteza, a instabilidade, a concorrência, e promovam a inovação de forma sistemática, é necessário dirigir a atenção para seu ambiente de trabalho, descontinuando barreiras e estimulando ações que potencializem as oportunidades para a criação e desenvolvimento das inovações. 
Para a maioria dos autores (HADJIMANOLIS, 2003; STANISLAWSKI; OLCZAK, 2010), as barreiras de inovação podem ser divididas em duas categorias: internas e externas. Assim, considera-se como barreiras internas aquelas que nascem nas próprias empresas e as barreiras externas como aquelas que surgem a partir do contexto no qual se insere o negócio.

Neste sentido, da mesma forma que o sistema vigente pode tornar-se uma barreira, ele também pode incentivar sua expansão. Em outras palavras, se o sistema se tornar social e economicamente difundido, ou se for justificada a sua manutenção (como a segurança nacional), os governos podem encorajar o desenvolvimento através de uma variedade de mecanismos, incluindo as subvenções, incentivos ou propriedade direta (UNRUH, 2000; FREEMAN; PEREZ, 1988).

Como apontado por autores como Zylbersztajn e Lins (2010) e Heloani (2005), a sobrevivência de algumas empresas está inserida na sua adaptação às novas necessidades sustentáveis do mercado e a direcionar seus esforços para atingir tais objetivos. Dentro dessa perspectiva, faz-se uso da transformação das barreiras em oportunidades para empresas e mercados, em busca do atendimento de necessidades, seja tecnológica ou não, de forma mais sustentável.

\subsection{Eco-inovação}

Drucker (2002) defende que a inovação pode tomar diferentes moldes, referindo-se à ideia de inovação sistemática, que consiste na busca e na exploração de novas oportunidades, tanto na área ambiental quanto econômica ou social, tendo como propósito o atendimento das necessidades e carências humanas.

Para Madrid-Guijarro, Garcia e Auken (2009) constataram que a inovação é o fator decisivo na competitividade das nações e empresas, sendo que as empresas que não abraçam a inovação em sua estratégia de negócio correm o risco de se tornarem não competitivas e obsoletas. Assim, as empresas inovadoras são um requisito para uma economia dinâmica e competitiva. Desse modo, Zylbersztajn e Lins (2010) argumentam que as organizações devem se adaptar ao ambiente mutável devido à necessidade de sobrevivência, sobretudo ao que se refere às inovações sustentáveis.

Ainda nesse sentido, Carrillo-Hermosilla, Del Río e Könnölä (2010) argumentam que as ecoinovações envolvem uma combinação de diferentes elementos que pertencem às esferas do design, modelo de negócios do produto/serviço, usuário e governança. Para os autores, 
enquanto a importância relativa dessas dimensões é mutável e pode variar com o ambiente que a organização está inserida, a ecoinovação tem o conceito pujante de se ter um impacto positivo sobre o meio ambiente.

A ferramenta da ecoinovação pode ser relevante para o sucesso do ambiente de inovação, considerando aspectos locais, sociais, culturais, ecológicos e econômicos (PUJARI, 2006). Como uma releitura da teoria de destruição criativa de Schumpeter (1961), a sobrevivência em longo prazo do sistema econômico depende da sua capacidade de criação e manutenção de processos econômicos sustentáveis, os quais envolvem a criação de valor e satisfação das necessidades atuais, sem comprometer as necessidades das gerações futuras (BELLEN, 2005).

Foxon e Andersen (2009) definem ecoinovação como sendo o tipo de inovação que é capaz de atrair rendas verdes/ecológicas ao mercado, reduzindo os impactos ambientais e criando valor para as organizações. Para Könnölä, Carrillo-Hermosilla e Gonzalez (2008), a ecoinovação se torna um processo de mudança sistêmica tecnológica e/ou social que consiste na criação de uma ideia e sua aplicação na prática da melhoria do desempenho ambiental. Segundo a OCDE (2010):

Ecoinovação será um fator-chave dos esforços do setor para enfrentar a mudança climática e realizar "crescimento verde" na era pós-Quioto. Ecoinovação exige uma mais rápida introdução de tecnologias de ponta e uma aplicação mais sistêmica de soluções disponíveis, inclusive as nãotecnológicas. Ela (ecoinovação) também oferece oportunidades para envolver novos jogadores, desenvolver novas indústrias e aumentar a competitividade. A mudança estrutural nas economias será imperativo nas próximas décadas (OCDE, 2010, p. 1).

De acordo com a OCDE (2009a, 2009b), a ecoinovação representa uma inovação que resulta numa redução do impacto ambiental. O âmbito da ecoinovação pode ir além dos limites convencionais das empresas em inovar, de forma que provoque modificações nas normas socioculturais e estruturas institucionais.

Segundo Camisón e López (2010), uma empresa inovadora tem maior capacidade para criar vantagens competitivas sustentáveis no mercado, seja incremental ou disruptiva, na medida em que apresenta maior flexibilidade na produção e melhor utilização dos seus recursos, de forma a gerar um desempenho superior.

Para o crescimento num ambiente dinâmico, a empresa deve ter a capacidade de criar e desenvolver sua forma de pensar e de atuar com a evolução do mercado. Schumpeter 
(1934), em seu pensamento de destruição criativa, no qual a destruição ocorre para a evolução de novos mercados, afirma que o processo-chave de desenvolvimento organizacional é a criação de novas combinações (de recursos, de competências e de processos), isto é, a criação e desenvolvimento da inovação de forma sustentável.

Bossel (1998) afirma que o conceito de desenvolvimento sustentável deve ser dinâmico, de forma que deve acompanhar as constantes mudanças da sociedade e do próprio meio ambiente. Tais mudanças ocorrem por fruto das inovações tecnológicas e alterações das culturas, valores e aspirações da sociedade, e devem estar embasadas no próprio ideal de sociedade sustentável. Todavia, o resultado dessas adaptações não pode ser previsto, pois decorrem de um processo evolucionário.

Assim, cresce a percepção de que a preservação do meio ambiente é condição necessária para a sustentabilidade dos negócios, e as práticas de gestão de empresas revelam o recente e contínuo desenvolvimento de políticas e ações voltadas para a sustentabilidade, integrando-a em suas estratégias e modelos de negócio. Em alguns ramos industriais, o tema sustentabilidade já se tornou pauta obrigatória, especialmente em relação à sobrevivência das empresas, pois caso não se adaptem às novas tendências sustentáveis podem deixar de praticar suas atividades (HELOANI, 2005).

A inovação é tema crucial para o posicionamento estratégico empresarial e para a permanência das empresas no mercado. É considerável a prática de desenvolvimento de atividades de inovação como fonte de competitividade e sustentabilidade das empresas. A acelerada competitividade do mercado e a extrema necessidade dos padrões de melhoria contínua impulsionam as empresas a desenvolver mecanismos de inovação.

A constante busca por adquirir e manter vantagens competitivas é considerada por Dunphy, Griffiths e Benn (2003) um agente de mudança, pois a otimização dos consumos (energéticos, recursos naturais, matéria-prima, etc.) reduz a probabilidade de ineficiências e produz um processo industrial ecológico e eficiente. Assim, é importante que o processo seja dinâmico e interativo com as estratégias de inovação, para eficiência no planejamento estratégico.

Hart e Milstein (2004) explicam que as empresas podem criar valor sustentável através da criação de novas tecnologias, redução da poluição e dos resíduos. O combate à poluição está focado no aumento da eficiência ambiental em produtos e processos e a redução de resíduos, na melhor utilização dos inputs. Segundo os autores, as organizações já pensam a 
sustentabilidade como parte da estratégia para geração de vantagem competitiva e de valor para a sociedade, produzindo benefícios econômicos, sociais e ambientais.

Em suma, a sustentabilidade global é um conceito complexo, multidimensional e que não pode ser equacionado através de uma única ação corporativa (HART; MILSTEIN, 2004). A criação de valor sustentável do marketing 3.0 é a forma mais sofisticada da era, centrada no consumidor, e demanda abordagens de marketing mais colaborativas, culturais e espirituais (KOTLER; KARTAJAYA; SETIAWAN, 2010).

Segundo Porter e Van der Linde (1995), as estratégias de inovação “verde”, podem garantir vantagem competitiva para as organizações nos aspectos de diferenciação e baixo custo dos produtos/produção, o que pode alterar as regras de concorrência existentes e determinar uma vantagem competitiva sustentável nos mercados (PORTER; VAN DER LINDE, 1995).

\section{METODOLOGIA}

Esta pesquisa se caracteriza como um estudo de caso de caráter descritivoexploratório. É descritivo, pois tem como objetivo principal descrever as características de um determinado fenômeno ou o estabelecimento de relações entre variáveis de estudo (YIN, 2010). Seu caráter exploratório busca "levantar novos questionamentos, pontos de partida e indagações que servirão a pesquisas futuras sobre o mesmo tema" (BERTUCCI, 2009, p. 4849).

Como forma de coleta de dados, este estudo de caso fez uso da triangulação, de modo a apresentar diferentes visões, percepções sobre um mesmo assunto abordado pelo pesquisador (YIN, 2010) nas quais foram utilizadas fontes de dados primárias e secundárias. Deste modo, foi realizada uma entrevista semiestruturada na Dell Inc. com o Diretor de Soluções Empresariais da empresa entre os meses de agosto e setembro de 2015. Em paralelo a isto, foi realizada uma pesquisa bibliográfica de base teórica, de material publicado em livros, artigos científicos, conteúdos disponibilizados na internet. Por fim, foi realizada uma pesquisa documental, que utilizou materiais oficiais relativos ao contexto da pesquisa, de forma que ampliem o resultado da análise (GIL, 2008).

O roteiro elaborado para este trabalho teve o intuito de conferir as práticas de ecoinovação utilizadas pela empresa pesquisada no mercado, seus investimentos em inovações da área, e seus ganhos de vantagem competitiva provenientes desta prática. Dessa 
forma, durante toda a pesquisa, o entrevistado foi incentivado a compartilhar experiências de mercado, o que traz um maior embasamento para o estudo realizado.

Como método de análise utilizou-se a análise de conteúdo, que consiste na fragmentação dos dados obtidos por meio da entrevista e dos documentos, em temas, ou categorias que foram analisados conforme as etapas propostas por Bardin (2016). Tais etapas são: pré-análise, no qual se realiza a codificação e organização do material; exploração do material, em que se retirou os trechos mais importantes, com base na grade fechada. Tal grade foi estabelecida conforme os tópicos do Plano Dell 2020 (DELL, 2013); e interpretação dos dados, que se refere à análise dos trechos e confronto dessa análise com a teoria.

\subsection{Seleção e apresentação do caso}

A Dell Inc. foi a empresa selecionada para ser foco deste estudo, visto que assumiu como parte de sua identidade, dentro do Plano Dell 2020 (DELL, 2013), que há oportunidades e benefícios para empresa com foco na sustentabilidade, como:

O desenvolvimento de soluções inovadoras para economias com baixa emissão de carbono, a expansão do uso de materiais mais sustentáveis, a geração de eficiências exponenciais em cadeias de suprimento globais e a descoberta de maneiras de reciclar e reutilizar materiais no caso de escassez de recursos. E vemos cada vez mais (DELL, 2013, p. 3).

O Plano para 2020 é a primeira etapa rumo à inserção profunda do compromisso sustentável no DNA da Dell, traduzido como objetivo do Marketing 3.0 de Kotler, Kartajaya e Setiawan (2010). A empresa "definiu a trajetória de como a sustentabilidade ambiental e social se tornará um acelerador para resultados sustentáveis e de sucesso para os clientes e a sociedade por muitos anos" (DELL, 2013, p. 3).

No âmbito documental, foi utilizado o Plano Dell 2020 (DELL, 2013), documento oficial da empresa que aplica a sustentabilidade como foco de ações do planejamento estratégico da organização a ser alcançado até o ano de 2020. Para o contexto, a pesquisa em profundidade foi realizada com um Diretor de Soluções Empresariais da Dell América Latina, que já passou também pelos cargos de Diretor de Marketing da Dell na América Latina e Diretor de Marketing da Dell Brasil.

Dividida em Unidades de Negócio, a Dell possui a área de End User Computing, ou seja, produtos para o utilizador final (Notebook, Desktop, Tablet, Monitor, etc.), e a área de Enterprises, que contempla a Dell Solution Center, responsável pela parte de clientes 
corporativos. O entrevistado concentra suas atividades na área de Clientes Corporativos, Dell Enterprises, responsável pela estrutura de Produtos para Servidores, Armazenamentos e Redes.

\section{RESULTADOS DA PESQUISA}

O presente tópico visa apresentar, analisar e discutir os resultados da pesquisa, de maneira a explorar o conteúdo apresentado no referencial teórico, acerca das inovações e ecoinovações como fontes de vantagem competitiva para oportunidades futuras no mercado.

Os dados presentes no Quadro 1 são apresentados pelo método descrito por Yin (1989) de padrão combinado, em que se objetiva comparar padrões empíricos com os padrões previstos, de maneira a ampliar ou não a validade interna dos dados. Os dados apresentados na seguinte análise contemplam a entrevista em profundidade realizada com o Gestor da Dell Inc., e com base na pesquisa documental realizada no Plano 2020, documento oficial de planejamento estratégico de ação da Dell.

\begin{tabular}{|c|c|}
\hline Autores & Perspectiva do Entrevistado e do Plano 2020 \\
\hline & Processos sustentáveis \\
\hline $\begin{array}{l}\text { Kotler, Kartajaya } \\
\text { e Setiawan } \\
\text { (2010); } \\
\text { Könnölä; } \\
\text { Carrillo- } \\
\text { Hermosilla; } \\
\text { Gonzalez (2008); } \\
\text { Dunphy; } \\
\text { Griffiths; Benn } \\
\text { (2003). }\end{array}$ & $\begin{array}{l}\text { Entrevista: } \\
\text { - Preocupação da empresa com todos os processos de manufatura a leva em } \\
\text { consideração a questão de ser sustentável. } \\
\text { - Priorizar o uso de materiais sustentáveis, com a utilização de materiais } \\
\text { biodegradáveis, equipamentos que tenham produtos recicláveis na sua construção } \\
\text { e no descarte dos mesmos (sendo todo o processo confidencial, sendo e parte do } \\
\text { segredo industrial da Companhia). } \\
\text { - Preocupação com uma redução de custos e ganho em escala, de maneira a } \\
\text { melhorar os negócios sustentáveis sem o que mesmo se torne inviável } \\
\text { financeiramente. } \\
\text { Plano Dell 2020: } \\
\text { Melhorias nos processos de reciclagem, produção sem poluição, utilização de lixo } \\
\text { agrícola na produção de embalagens, redução do uso de energias e diminuição do } \\
\text { uso de produtos químicos. }\end{array}$ \\
\hline
\end{tabular}

\section{Consumo de energia}

\begin{tabular}{|c|c|}
\hline $\begin{array}{l}\text { Carrillo- } \\
\text { Hermosilla, Dell } \\
\text { Río e Könnölä } \\
\text { (2008); } \\
\text { Dunphy; } \\
\text { Griffiths; Benn } \\
\text { (2003); } \\
\text { Manual de Oslo }\end{array}$ & $\begin{array}{l}\text { Entrevista: } \\
\text { - Diminuição do uso de recursos naturais, de maneira a não se opor a necessidade } \\
\text { do mercado. } \\
\text { - Manter o padrão em todos os níveis e estão implantados no planejamento de longo } \\
\text { prazo, em busca de portfólio com menos consumo de energia, e um benefício } \\
\text { financeiro e sustentável para os clientes. } \\
\text { - Preocupação em ser competitivo, mantendo a qualidade e preocupação com os } \\
\text { descartes futuros, mas a primeira prioridade de qualquer programa de }\end{array}$ \\
\hline
\end{tabular}




\begin{tabular}{l|l}
\hline (2008). & $\begin{array}{l}\text { sustentabilidade é ser o mais eficiente possível, consumindo menos recursos ou } \\
\text { criando menos lixo. }\end{array}$ \\
\hline
\end{tabular}

\section{Barreiras e limitações}

Pinheiro (2002);

Zylberstajn e

Lins (2010).

\section{Entrevista:}

- Dificuldade em controlar toda a cadeia de produção para garantir que $100 \%$ do ecossistema em que a empresa está inserida possui o mesmo comprometimento.

- Fomentar as atividades dos fornecedores e parceiros em busca de resultados mais sustentáveis.

- Preocupação da utilização da sustentabilidade como ganho de marketing, sem a prática em si, o que torna difícil realizar projetos sustentáveis quando o ambiente (corporativo ou não) ainda não busca esta prática.

- Como solução para os problemas de disseminação das práticas sustentáveis, o ganho em escala e redução de custo, para que produtos não sejam proibitivos, evitando a morte dos negócios.

- A dissonância que ocorre, na opinião do entrevistado, entre Estado, cidadão, empresas e órgãos não governamentais, não convergindo para os ideais sustentáveis.

Plano Dell 2020:

- Apontado como o maior desafio: encontrar suprimentos que protejam os produtos assim como os materiais não sustentáveis fazem e uma busca constante pela melhoria da eficiência energética.

\section{Marketing}

\begin{tabular}{l|l}
\hline $\begin{array}{l}\text { Kotler, Kartajaya } \\
\text { e Setiawan }\end{array}$ & $\begin{array}{l}\text { Entrevista: } \\
\text { (2010); }\end{array}$ \\
$\begin{array}{l}\text { Pujari (2006). } \\
\text { Os pontos admitidos como primordiais para o produto passam pela qualidade, } \\
\text { performance, preço (justo) e a satisfação do usuário, seja ele usuário final ou } \\
\text { corporativo. }\end{array}$ \\
$\begin{array}{l}\text { A importância dada à satisfação (e sustentabilidade) para o usuário no que é } \\
\text { visível do produto, mas também no que ele não é visível, de maneira a fazer a } \\
\text { diferença na entrega do produto final. }\end{array}$ \\
\hline
\end{tabular}

\section{Inovação e Ecoinovação}

\begin{tabular}{|c|c|}
\hline $\begin{array}{l}\text { Schumpeter } \\
\text { (1939); Kotler, } \\
\text { Kartajaya e } \\
\text { Setiawan (2010); } \\
\text { Manual de Oslo } \\
\text { (2008); } \\
\text { Carrillo- } \\
\text { Hermosilla Del } \\
\text { Rio e Könnölä } \\
\text { (2010). }\end{array}$ & $\begin{array}{l}\text { - Entrevista: } \\
\text { Utilização de tecnologias para acelerar detecção de doenças genoma e cura do } \\
\text { câncer, desenvolvimento sem visão de lucro, atendendo diferentes pontos da } \\
\text { sustentabilidade. } \\
\text { - O componente ecoinovação como uma oportunidade de mercado, de forma a } \\
\text { caminhar para uma geração de produtos, serviços, soluções e materiais mais } \\
\text { orgânicos ou mais ecos. } \\
\text { Plano Dell 2020: } \\
\text { Desenvolvimento de soluções inovadoras para economias com baixa emissão de } \\
\text { carbono, a expansão do uso de materiais mais sustentáveis, a geração de } \\
\text { eficiências exponenciais em cadeias de suprimento globais e a descoberta de } \\
\text { maneiras de reciclar e reutilizar materiais no caso de escassez de recursos. }\end{array}$ \\
\hline
\end{tabular}

\section{Planejamento estratégico}

Vieira e Tibola
$(2005)$;
Kotler, Kartajaya
e Setiawan
$(2010)$.

\section{Plano Dell 2020:}

- O manifesto apresentado pela empresa possui objetivos sustentáveis claros para serem atingidos até o ano de 2020, tornando as práticas sustentáveis parte do seu Planejamento Estratégico.

- A estratégia da Companhia visa transformar comunidades por meio da tecnologia, utilizada como bem global, de maneira a buscar ferramentas para alterar as 
comunidades a que está inserida.

\section{Investimentos em P\&D}

\begin{tabular}{|c|c|}
\hline $\begin{array}{l}\text { Kotler, Kartajaya } \\
\text { e Setiawan } \\
(2010) \text {; } \\
\text { Könnölä, } \\
\text { Carrillo- } \\
\text { Hermosilla e } \\
\text { Gonzalez (2008); } \\
\text { Drucker (2002); }\end{array}$ & $\begin{array}{l}\text { Entrevista: } \\
\text { - Apensar de não apresentados os números de investimento em P\&D por se tratarem } \\
\text { de informação confidencial, a pesquisa apresentou a questão do avanço do } \\
\text { portfólio que, em consequência, traz práticas e processos mais ecológicos, busca } \\
\text { substituição por uma manufatura biodegradável ou que possa ser reciclada, } \\
\text { tornando o produto em si mais sustentável. } \\
\text { - A pesquisa aponta que não há uma política clara de um produto "eco", mas que } \\
\text { todos os micro processos sejam mais ecológicos, de maneira a alcançar o resultado } \\
\text { mais sustentável. } \\
\text { Plano Dell 2020: } \\
\text { - São pontuadas como oportunidades para empresas com foco na sustentabilidade: } \\
\text { soluções inovadoras com baixa emissão de carbono, expansão do uso de materiais } \\
\text { mais sustentáveis, geração de eficiências em cadeias de suprimento globais e a } \\
\text { descoberta de maneiras de reciclar e reutilizar materiais no caso de escassez de } \\
\text { recursos. } \\
\text { Outro grande desafio/oportunidade assumido pela empresa é a busca por materiais } \\
\text { alternativos que atendam aos requisitos de performance, de maneira a ganhar } \\
\text { flexibilidade nos produtos e processos. }\end{array}$ \\
\hline
\end{tabular}

Valor e Vantagem Competitiva

\begin{tabular}{|c|c|}
\hline $\begin{array}{l}\text { Hart e Milstein } \\
\text { (2004); } \\
\text { Porter (1989); } \\
\text { Freeman (1988); } \\
\text { Kotler, Kartajaya } \\
\text { e Setiawan } \\
\text { (2010); } \\
\text { Porter e Van der } \\
\text { Linde (1995); } \\
\text { Zylberstajn e } \\
\text { Lins (2010). }\end{array}$ & $\begin{array}{l}\text { Entrevista: } \\
\text { - Conforme apontado na pesquisa, o componente financeiro faz parte do mercado, e } \\
\text { é o mesmo que financia constantes pesquisas de maneira a progredir em melhores } \\
\text { produtos e processos. } \\
\text { Plano Dell 2020: } \\
\text { - A pesquisa aponta para a estratégia de responsabilidade ambiental como parte das } \\
\text { vantagens no fornecimento de valor para os clientes/mercado. } \\
\text { - A Companhia acredita que, à medida que os negócios se expandirem e evoluírem } \\
\text { na próxima década, as organizações que satisfizerem as necessidades ambientais } \\
\text { para produtos e processos terão uma incrível vantagem competitiva no mercado. }\end{array}$ \\
\hline
\end{tabular}

Quadro 1 - Confronte entre Base Teórica, Pesquisas e Relatos Fonte: Adaptado dados Pesquisa.

Conclusão

Com base nos dados apresentados, é possível verificar que a empresa valoriza as práticas sustentáveis da inovação, tendo uma grande preocupação com o desenvolvimento de processos mais sustentáveis, utilização de materiais biodegradáveis e a reciclagem de seus produtos. Dentro deste patamar, as práticas de inovação voltadas para bases sustentáveis são uma fonte de vantagem competitiva visto que as mesmas podem conferir um diferencial de fornecimento de materiais e produtos aprimorados ao mercado, seja ele corporativo ou final (KOTLER; KARTAJAYA; SETIAWAN, 2010).

A empresa foco deste estudo, dentro do ambiente de inovação, está em um desenvolvimento desta prática no mercado, buscando novos produtos, processos ou mudança 
organizacional ao se posicionar frente às oportunidades futuras do mercado. A pesquisa aponta para foco em inovações, para a evolução das atividades do mercado, de maneira a ganhar escala em processos, e tornar produtos e processos mais viáveis para continuidade das atividades organizacionais de todos os mercados.

Deve-se considerar na pesquisa a existência de uma visão capitalista nos negócios, mas também a busca por uma sustentabilidade em produtos, processos, na organização e mercado, que, na qualidade de empresa fornecedora de soluções informáticas, visualiza como uma oportunidade para satisfazer necessidades organizacionais futuras em um cenário de restrições energéticas e de materiais.

Neste sentido, é importante ressaltar e considerar as oportunidades que a própria organização adquire, como corte de custos, a conservação de recursos, a obtenção de novas oportunidades de negócios e a definição de percepções de marca. De maneira sustentável, a atuação da Companhia também se torna uma grande oportunidade para se posicionar no mercado com as soluções globais para o problema de falta de acesso, se tornando uma opção viável para inclusão tecnológica, em contrapartida à oferta de produto.

Tendo como intuito das empresas capitalistas o desenvolvimento de negócios presentes e futuros, o resultado da entrevista, assim como o posicionamento da empresa no manifesto apresentado, deixa clara a percepção da Companhia com relação às vantagens competitivas futuras das práticas de ecoinovação, englobando no seu planejamento estratégico o desenvolvimento desta prática para as oportunidades de mercados ainda inexplorados (PORTER; VAN DER LINDE, 1995; KOTLER; KARTAJAYA; SETIAWAN, 2010).

\section{CONSIDERAÇÕES FINAIS}

O presente trabalho foi produzido com o objetivo de estudar as práticas de ecoinovação tratada dentro do ambiente da pesquisa como inovação sustentável, e as possíveis vantagens competitivas que a Dell Inc. pode obter frente ao mercado. É importante ressaltar que, dentro do ambiente pesquisado, pode-se determinar que a empresa possui elevado índice de práticas que envolvem as inovações sustentáveis. Porém, fica claro também a visão capitalista da empresa, que busca oportunidades que os novos mercados sustentáveis ofertam.

A empresa, com sua capacidade global de afetar mercados, busca, através de suas relações com os ambientes, solucionar as necessidades tecnológicas que pessoas, 
organizações, comunidades e mercados possuem, dentro de um universo mais sustentável e de olho nas exigências e restrições mercadológicas futuras.

É possível inferir que as práticas da empresa inquerida, dividida nas categorias do Plano Dell 2020, possuem uma forte relação voltada para as ecoinovações, dentro das divisões de produto, processos, organizacional e mercadológica, de maneira enraizada no seu planejamento estratégico, como um DNA, conforme apontado por Kotler, Kartajaya e Setiawan (2010). Obteve-se também pelas pesquisas, que as práticas de ecoinovação precisam de redução de custos, ganho em escala e transformar as barreiras restritivas em oportunidades, gerando novos produtos e mercados, para que as mesmas se tornem vantagens competitivas.

É possível concluir que há relação entre as bases teóricas e as bases da pesquisa (apresentados no Quadro 1), visto que estão em comum acordo com a literatura do tema, principalmente em relação às necessidades e oportunidades para as empresas no mercado, de maneira que a Companhia pesquisada se posiciona frente a este novo modelo de mercado.

A pesquisa bibliográfica realça ainda a importância da sustentabilidade para os mercados futuros, como proposto por Kotler, Kartajaya e Setiawan (2010), sendo essa a premissa para o Marketing 3.0. Assim, os produtos, processos, organizações e mercados, tal como apontado por Schumpeter (1939), podem se adaptar às necessidades e oportunidades sustentáveis e criar valor às inovações sustentáveis, tornando-as parte da estratégia e existência da empresa.

Portanto, as premissas de Kotler, Kartajaya e Setiawan (2010), Schumpeter (1939), Heloani (2005) e Zylberstajn e Lins (2010) reforçam os resultados da pesquisa, bem como enfatizam que as inovações sustentáveis, ou ecoinovações, são a chave para sobrevivência das organizações em mercados futuros. Ou seja, as ecoinovações são ferramentas importantes para determinar a competitividade das organizações.

Por fim, pode-se verificar que ocorre com relação entre as práticas de ecoinovação e ganhos para o mercado, visto que esta última se apresenta como oportunidade para satisfazer as necessidades mais recentes da sociedade e do mercado. Dessa maneira, é possível considerar que a empresa pesquisada, dentro de seu escopo de atuação, acredita que as inovações sustentáveis podem garantir uma vantagem competitiva, seja no desenvolvimento de novas tecnologias, soluções ou materiais para o mercado. 


\title{
ECOINNOVATION AS A COMPETITIVE ADVANTAGE: A CASE STUDY OF DELL INC.
}

\begin{abstract}
The rising market concerns on sustainable activities create opportunities for the firms' positioning, which can use these to increase competitiveness. However, it is necessary to understand deeply the phenomenon of eco-innovation (or sustainable innovations) in order to leverage competitive assets and keep to date with the economic trends. This article presents a case study of eco-innovation practices at Dell Inc., seeking to understand how these can become a source of competitive advantage for the firm. A descriptive-exploratory study was carried out, in which data were collected through a semi-structured interview and a documentary research on the Dell 2020 Plan. In accordance with the reviewed literature, the results indicate that Dell presents a high index of eco-innovative practices and, at the same, it presents visions, new opportunities and new markets due to these same practices.
\end{abstract}

Keywords: Innovation. Eco innovation. Dell. Competitive advantage.

\section{REFERÊNCIAS}

BARDIN, Laurence. Análise de conteúdo. Lisboa: Edições 70, 2016. 225 p.

BELLEN, Hans Michel Van (Org.). Indicadores de sustentabilidade. Rio de Janeiro: FGV, 2005.

BERTUCCI, Janete Lara de Oliveira. Metodologia básica para elaboração de trabalhos de conclusão de curso (TCC): ênfase na elaboração de TCC de pós-graduação lato sensu. São Paulo: Atlas, 2009.

BOSSEL, Hartmut. Earth at a crossroads: paths to a sustainable future. Cambridge: Cambridge University Press, 1998.

BOWER, Joseph L.; CHRISTENSEN, Clayton M. Disruptive Technologies: catching the wave. Harvard Business Review, v. 73, n. 1, p. 43-53, jan./feb. 1995.

CAMISÓN, César; LÓPEZ, Ana Villar. An examination of the relationship between manufacturing flexibility and firm performance: the mediating role of innovation. International Journal of Operations \& Production Management, v. 30, n. 8, p. 853-878, 2010 .

CARRILLO-HERMOSILLA, Javier; DEL RÍO, Pablo; KÖNNÖLÄ, Totti. Diversity of ecoinnovations: reflections from selected case studies. Journal of Cleaner Production, v. 18, p. 1073-1083, 2010. 
CARRILLO-HERMOSILLA, Javier; DEL RÍO, Pablo; KÖNNOLA, Totti. Eco-innovation. When Sustainability and Competitiveness Shake Hands. Palgrave, London, 2008.

DELL. Dell 2020 Legacy of Good Plan. 2013. Disponível em: <http://www.dell.com/learn/us/en/ uscorp1/2020-goals>. Acesso em: 06 jun 2015. DRUCKER, Peter. The Discipline of Innovation. Harvard Business Review, v. 80, p. 95104, 2002.

DUNPHY, Dexter; GRIFFITHS, Andrew; BENN, Suzanne. Organizational change for corporate sustainability: a guide for leaders and change agents of the future. New York: Routledge, 2003. 315 p.

FOXON, Timothy; ANDERSEN, Maj Munch. The greening of innovation systems for ecoinnovation: towards an evolutionary climate mitigation policy. In: DRUID SUMMER CONFERENCE: Innovation, Strategy and Knowledge, 2009, Copenhagen. Proceedings... Copenhagen: DRUID Society, 2009.

FREEMAN, Christopher. Technical change and economic theory. Londres: Pinter Publishers, 1988.

FREEMAN, Christopher; PEREZ, Carlotta. Structural crisis of adjustment, business cycles and investment behaviour. Technical Change and Economic Theory. London: Pinter Publishers, p. 38-66, 1988.

GIL, Antônio Carlos. Métodos e técnicas de pesquisa social. São Paulo: Atlas, 2008.

HADJIMANOLIS, Athanasios. The barriers approach to innovation. In: SHAVININA, Larisa V. (Ed.). The international handbook in innovation. Oxford, UK: Elsevier Science, 2003. p. 559-573.

HART, Stuart L., MILSTEIN, Mark B. Criando valor sustentável. Revista Eletrônica RAE Executivo, São Paulo, n. 2, 2004. Disponível em: <http://rae.fgv.br/gv-executivo/vol3-num22004/criando-valor-sustentavel>. Acesso em: 06 maio 2015.

HELOANI, Roberto. Sustentabilidade e bons negócios. Revista Eletrônica RAE Executivo, São Paulo, n. 1, 2005. Disponível em: <http://rae.fgv.br/gv-executivo/vol4-num1-2005/ sustentabilidade-bons-negocios>. Acesso em: 14 maio 2015.

KÖNNÖLÄ, Totti; CARRILLO-HERMOSILLA, Javier; GONZALEZ, Pablo del Rio. Dashboard of ecoinnovation. In: DIME INTERNATIONAL CONFERENCE: Innovation, sustainability and policy, 2008, Pessac, France. Proceedings... Pessac, France: University Montesquieu Bordeaux IV, 2008. 
KOTLER, Philip; KARTAJAYA, Hermawan; SETIAWAN, Iwan. Marketing 3.0: as forças que estão definindo o novo marketing centrado no ser humano. Rio de Janeiro, Elsevier Editora Ltda, 2010.

MADRID-GUIJARRO, Antônia; GARCIA, Domingo; AUKEN, Howard Van. Barriers to innovation among Spanish manufacturing SMEs. Journal of Small Business Management, v. 47, n.4, p. 465-488, 2009.

MANUAL DE OSLO. Proposta de diretrizes para coleta e interpretação de dados sobre inovação tecnológica. [S. 1.]: OCDE; FINEP, 2008. Disponível em: <http://download. finep.gov.br/imprensa/manual_de_oslo.pdf>. Acesso em: 20 abr. 2015.

ORGANIZAÇÃO PARA A COOPERAÇÃO E DESENVOLVIMENTO ECONOMICO (OCDE). Eco-Innovation in Industry: Enabling Green Growth. OECD Multilingual Sumaries. Paris, 2010. Disponível em: <http://www.oecd.org/sti/ind/ecoinnovationinindus tryenablinggreengrowth.htm>. Acesso em: 01 jun. 2015.

ORGANIZAÇÃO PARA A COOPERAÇÃO E DESENVOLVIMENTO ECONOMICO (OCDE). Sustainable manufacturing and eco-innovation. Framewok, practices and measurement. Synthesis report. Paris, 2009a. Disponível em: <www.oecd.org/sti/innovation/ sustainablemanufacturing>. Acesso em: 20 abr. 2015.

ORGANIZAÇÃO PARA A COOPERAÇÃO E DESENVOLVIMENTO ECONOMICO (OCDE). Sustainable manufacturing and eco-innovation: towards a green economy. Policy Brief, 2009b. Disponível em: <https://www.oecd.org/env/consumption-innovation/ 42957785.pdf >. Acesso em: 20 abr. 2015.

PINHEIRO, Ivan Antônio. Fatores do clima organizacional que são motivadores para a inovação tecnológica em um centro de tecnologia. Revista Eletrônica de Administração, Porto Alegre, ed. 29, v. 8, n. 5, set./out. 2002.

PORTER, Michel. A vantagem competitiva das nações. Rio Janeiro: Campus, 1989.

PORTER, Michel; VAN DER LINDE, Claas. Green and competitive: ending the stalemate. Harvard Business Review, v. 33, p. 120-134, 1995.

PUJARI, Devashish. Eco-innovation and new product development: understanding the influences on market performance. Technovation, v. 26, n. 1, p. 76-85, 2006.

SCHUMPETER, Joseph Alois. Capitalism, Socialism and Democracy. New York, NY: Harper and Row, 1950.

SCHUMPETER, Joseph Alois. Capitalismo, Socialismo e Democracia. Rio de Janeiro: Fundo de Cultura, 1961. 
SCHUMPETER, Joseph Alois. The theory of economic development: an inquiry into profits, capital credit, interest and the business cycle. Cambridge: Harvard Business Press, 1939.

SCHUMPETER, Joseph Alois. The theory of economic development. Cambridge: Harvard University Press, Cambridge Massachusetts, 1934.

STANISLAWSKI, Robert; OLCZAK, Artur. Innovative activity in the small business setor of the textile and clothing industry. Fibres \& Textiles in Eastern Europe, v. 18, n. 1, p. 13-16, 2010 .

UNRUH, Gregory. Understanding carbon lock-in. Energy Policy, v. 28, n. 12, p. 817-830, 2000.

VIEIRA, Valter Afonso; TIBOLA, Fernando. Pesquisa qualitativa em marketing e suas variações: trilhas para pesquisas futuras. Revista de Administração Contemporânea, Curitiba, v. 9, n. 2, p. 9-33, 2005.

YIN, Robert. Case study research: design and methods. Newbury Park: Sage, 1989. 166 p.

YIN, Robert. Estudo de caso: planejamento e métodos. Porto Alegre: Bookman, 2010.

ZYLBERSZTAJN, David; LINS, Clarissa. Sustentabilidade e geração de valor: a transição para o século XXI. Rio de Janeiro: Campus, 2010.

\section{DADOS DOS AUTORES}

\section{João Paulo Nascimento da Silva}

E-mail: jpnsilvas@gmail.com

Currículo Lattes: http://lattes.cnpq.br/9917187297657200

Mestrado em andamento em Administração - Universidade Federal de Lavras (UFLA), Mestre em Marketing Relacional - Instituto Politécnico de Leiria (IPLeiria, Portugal), Graduado em Administração de Empresas pelo Instituto Vianna Júnior (FGV)" após o MBA na UFJF, Especialização em MBA Gestão de Negócios e Empreendimentos - Universidade Federal de Juiz de Fora (UFJF), Professor da Faculdade de São Lourenço (FSL), União das Instituições de Serviço, Ensino e Pesquisa (UNISEPE), Brasil.

\section{Vitor Hugo Santos Ferreira}

E-mail: vitor.ferreira@gmail.com

Orcid: https://orcid.org/0000-0003-3400-5996

$\mathrm{PhD}$ (Economics and Management) - Instituto Superior de Economia e Gestão: Lisboa, Portugal, Master on Management of Science, Technology and Innovation - Instituto Superior de Economia e Gestão: Lisboa, Portugal, Associate Professor (Management and Economics) - Instituto Politécnico de Leiria (IPL), Portugal. 


\section{Rodrigo Marçal Gandia}

E-mail: romgandia@gmail.com

Currículo Lattes: http://lattes.cnpq.br/7722804089491117

Mestre em Administração - Universidade Federal de Lavras (UFLA), Especialização em

MBA Gestão de Pessoas - Business School - Fundação Getúlio Vargas (IBS-FGV).

\section{Luiz Guilherme Rodrigues Antunes}

E-mail: luguiantunes@yahoo.com.br

Currículo Lattes: http://lattes.cnpq.br/2461245570201384

Mestre em Administração - Universidade Federal de Lavras (UFLA), Especialização em MBA Executivo - Universidade Federal de Itajubá (UNIFEI), Professor Instituto Federal de Minas Gerais Campus de Formiga (IFMG), Brasil.

\section{Joel Yutaka Sugano}

E-mail: joel.sugano@gmail.com

Currículo Lattes: http://lattes.cnpq.br/6646670020755884

Doutorado em Doctoral Program in Japanese Economy and Business - Osaka University, OsakaU, Japão, Mestre em Administração - Universidade Federal de Lavras (UFLA), Professor do Departamento de Administração e Economia da Universidade Federal de Lavras (UFLA), Brasil. 